\title{
MELATIH KEARIFAN INTELEKTUAL, EMOSIONAL, DAN SPIRITUAL PEMUDA GUNA MENGHADAPI PASAR BEBAS ASIA TENGGARA (MASYARAKAT EKONOMI ASEAN-MEA)
}

\author{
Ana Andriani \\ Fakultas Keguruan Ilmu Pendidikan, Universitas Muhammadiyah Purwokerto, \\ email: ana.andriani@gmail.com
}

\begin{abstract}
Youth is the hope of the nation that has a great responsibility for the future of the nation and country. A heavy burden on his shoulders has its own consequences, which the youth must be able to work and participate in development. Youth with all its potential has an important role in the future life. Therefore, the youth must master in soft skills and hard skills to be able to compete with other nations in the world. This paper describes the role of the youth to build a nation with wisdom, intellectual, emotional, and spiritual needs to have to face the various challenges of the times. Similarly, the readiness of the youth needed both physically and psychologically in order to welcome the free market of Southeast Asia / ASEAN Economic Community (MEA) is imminent. Youth with all the benefits expected to be the generation that is better than the previous generation, so that the nation still exist in the eyes of the world. Through the study of literature describes how the role of youth in the face of global challenges to be enactment of Asian Economic Community (MEA) will be presented very competitive. In addition to the example and support that should be provided by parents, governments, and private parties as well as other related exercise wisdom, intellectual, emotional, and spiritual youth should be conducted on an ongoing basis in order to anticipate things that are not desirable. Global challenges and competition from various nations is expected to increase wisdom, intellectual, emotional, and spiritual.
\end{abstract}

Keywords: Wisdom intellectual, emotional, spiritual, youth, Southeast Asian Free Market (Economic Community Asia-MEA)

\begin{abstract}
ABSTRAK
Pemuda adalah harapan bangsa yang memiliki tanggung jawab besar untuk masa depan bangsa dan negaranya. Beban berat di pundaknya memiliki konsekuensi tersendiri, bahwa para pemuda harus mampu berkarya dan berpartisipasi dalam pembangunan. Pemuda dengan berbagai potensinya memiliki peran penting bagi kehidupan di masa depan. Untuk itu, pemuda harus menguasai softskill dan hardskill agar mampu berkompetisi dengan bangsa-bangsa lainnya di dunia ini. Artikel ini menjelaskan tentang peran pemuda untuk membangun bangsa dengan kearifan intelektual, emosional, dan spiritual yang harus dimilikinya untuk menghadapi berbagai tantangan zaman. Demikian juga diperlukan kesiapan pemuda baik secara fisik maupun psikis guna menyambut pasar bebas Asia Tenggara/ Masyarakat Ekonomi ASEAN (MEA) yang sudah diambang pintu. Pemuda dengan segala kelebihannya diharapkan menjadi generasi yang lebih baik dari generasi sebelumnya, sehingga bangsa tersebut tetap eksis di mata dunia. Melalui metode studi literatur untuk menjelaskan tentang bagaimana peran pemuda dalam menghadapi tantangan global dengan akan diberlakukannya Masyarakat Ekonomi Asia (MEA) yang sangat kompetitif akan dipaparkan. Selain teladan dan dukungan yang harus diberikan oleh orang tua, pemerintah, dan swasta serta pihak-pihak yang terkait lainnya, melatih kearifan intelektal, emosional, dan spiritual para pemuda harus dilaksanakan secara berkesinambungan guna mengantisipasi hal-hal yang tidak diinginkan. Tantangan global serta kompetisi dengan berbagai bangsa diharapkan mampu meningkatkan kearifan intelektual, emosional, dan spiritual.
\end{abstract}

Kata kunci: Kearifan intelektual-emosional-spiritual, pemuda, Pasar Bebas Asia Tenggara (Masyarakat Ekonomi Asia-MEA). 


\section{PENDAHULUAN}

Bangsa Indonesia saat ini mengalami krisis multidimensional. Permasalahan yang ada sangat kompleks, dari mulai issu HAM (Hak Asasi Manusia), pembalakan hutan, penangkapan ikan secara ilegal, kekerasan terhadap anak, korupsi, demonstrasi anarkis yang mencoreng wajah demokrasi, sampai kasus asap di beberapa wilayah Indonesia yang telah banyak memakan korban, sampai saat ini belum dapat diatasi. Dari sekian banyak fenomena yang ada, masalah sikap dan perilaku dapat dijadikan sebagai catatan penting. Sikap masyarakat Indonesia yang sangat terkenal dengan adat ketimurannya seperti keramahan dan kesopanan yang senantiasa menjadi ciri khas masyarakat Indonesia digantikan dengan tindakan-tindakan anarkis yang sering dipertontonkan pada saat berdemonstrasi menentang berbagai kebijakan pemerintah. Individualis, liberalis, dan sekularis bahkan menjadi panutan.

Perkembangan ilmu pengetahuan dan teknologi telah banyak merubah perilaku manusia. Banyak kemudahan yang dapat diraih oleh manusia untuk pemenuhan kebutuhannya. Namun tak sedikit pengetahuan menjadi bumerang bagi manusia itu sendiri. Ketepatan dan kecepatan dalam menggunakan waktu menjadi faktor penting saat ini. Demikian halnya dengan kesempatan yang dapat diambil oleh para pemuda baik dalam lingkup lokal, nasional, maupun global. Akan diberlakukannya MEA (Masyarakat Ekonomi Asia) di kawasan Asia Tenggara membawa warna tersendiri, Fenomena sosial yang sangat menghawatirkan dan sekarang kita akan menghadapi pasar bebas Asia Tenggara, Pertanyaannya adalah, sanggupkan masyarakat Indonesia khususnya para pemuda berkompetisi di pasar bebas MEA ini?

\section{PEMBAHASAN}

\section{Kearifan Intelektual, Emosional, Spiritual}

Aspek Intelektual, emosional, dan spiritual menjadi unsur-unsur penting dalam kehidupan manusia. Hal ini diperlukan guna menghadapi berbagai tantangan global. Fenomena sosial memperlihatkan bahwa produk perkembangan ilmu pengetahuan dan teknologi canggih menjadikan perilaku manusia mengalami banyak perubahan. Kondisi baru membuat masyarakat mengalami gagap budaya, dan gagap teknologi. Karakteristik unik dari situasi dan kondisi baru menjadikan masyarakat memerlukan adaptasi terlbih dahulu. Selain itu, diperlukan juga kesiapan fisik dan psikis untuk menghadapinya. Pasar bebas Asia tenggara yang sudah di depan mata hendaknya disikapi dengan sebaik-baiknya, sehingga bangsa Indonesia betul-betul siap baik fisik maupun psikis untuk mengantisipasi terjadinya hal-hal yang tidak diinginkan.

Arif bermakna bijaksana, berilmu seperti dijelaskan dalam Kamus Besar Bahasa Indonesia yakni bijaksana; cerdik dan pandai; berilmu http://kbbi.web.id/arif. Kata kearifan yang bermakna kebijaksanaan, sering disandingkan dengan kata lokal. Kearifan Lokal di sini diterjemahkan sebagai Local Wisdom (definisi kamus) dan atau Local Genius (istilah antropologi yang dipopulerkan oleh Quaritch Wales). Kearifan lokal disepakati sebagai keunggulan budaya masyarakat setempat maupun kondisi geografis dalam arti luas.

Kearifan lokal merupakan produk budaya masa lalu yang patut secara terus-menerus dijadikan pegangan hidup. Meskipun bernilai lokal tetapi nilai yang terkandung di dalamnya dianggap sangat universal. Kata kearifan sarat makna dengan nilai luhur tentang sikap bijaksana. Kata bijaksana sering disandingkan pada kata arif tersebut untuk menunjukkan perilaku mulia yang diperlihatkan oleh seseorang yang berilmu. Arif bijaksana menunjuk sebuah sifat, dan kearifan bermakna benda. Sikap Arif bijaksana diharapkan dapat tercermin dalam sikap perilaku bangsa Indonesia dalam menghadapi berbagai permasalahan yang ada. Kearifan tidak selalu datang dari orang tua, kearifan juga dapat datang dari kedewasaan pemuda yang mampu mengelola pikiran, ucapan dan perilakunya dengan baik.

Intelektual dapat diartikan: cerdas, berakal, dan berpikiran jernih berdasarkan ilmu pengetahuan; (yang) mempunyai kecerdasan tinggi; cendekiawan; totalitas pengertian atau kesadaran, terutama yang menyangkut pemikiran dan pemahaman. Seseorang yang memiliki keahlian untuk hidup (profesi) sehingga dia mampu hidup mandiri dan tidak mudah dipengaruhi orang lain, merupakan terjemahan bebas dari intelektual. Definisi intelektual itu sendiri menurut Gunarsa (1991) 
intelektual merupakan suatu kumpulan kemampuan seseorang untuk memperoleh ilmu pengetahuan dan mengamalkannya dalam hubungannya dengan lingkungan dan masalahmasalah yang timbul. Selanjutnya Cattel (dalam Clark, 1983), intelektual adalah kombinasi sifat-sifat manusia yang terlihat dalam kemampuan memahami hubungan yang lebih kompleks, semua proses berfikir abstrak, menyesuaikan diri dalam pemecahan masalah dan kemampuan memperoleh kemampuan baru. intelektual sebagai kumpulan atau totalitas kemampuan seseorang untuk bertindak dengan tujuan tertentu, berpikir secara rasional, serta menghadapi lingkungan secara efektif. David Wechsler (dalam Saifuddin Azwar, 1996, https://www.facebook.com/KomunitasIlmiahM ahasiswa/posts/358636784231276).

Dari beberapa definisi tentang Intelektual, dapat dimaknai sebagai suatu kemampuan yang dilandasi ilmu pengetahuan untuk menyelesaikan berbagai permasalahan kompleks menggunakan menalar, serta bertindak secara efisien dan efektif (http://kbbi.web.id/intelektual). Hasil penelitian Goleman (2003) menunjukkan kemampuan terbesar yang mempengaruhi kesuksesan seseorang dalam bekerja adalah empati, disiplin diri dan inisiatif yang dikenal dengan nama kecerdasan emosional. Bahwa keberhasilan hidup seseorang ditentukan pendidikan formalnya 15\% sedangkan $85 \%$ lagi ditentukan oleh sikap mentalnya/kepribadiannya (Mangkunegara, 2010). Ini memperlihatkan bahwa pendidikan formal memberi kontribusi sedikit untuk kesuksesan individu.

Emosi menurut Goleman (1995) adalah setiap kegiatan atau pergolakan pikiran, perasaan, nafsu, setiap keadaan mental yang hebat dan meluap-luap. Emosi merujuk kepada suatu perasaan dan pikiran-pikiran yang khas, suatu keadaan biologis dan psikologis, dan serangkaian kecendrungan untuk bertindak. Emosi juga merupakan perasaan intens yang ditujukan kepada seseorang atau sesuatu, juga sebagai reaksi terhadap seseorang atau kejadian. Emosi dapat ditunjukkan ketika merasa senang mengenai sesuatu, marah kepada seseorang, ataupun takut terhadap sesuatu. Chaplin (1989) dalam Dictionary of psychology, menjelaskan makna emosi adalah sebagai suatu keadaan yang terangsang dari organisme mencakup perubahan-perubahan yang disadari, yang mendalam sifatnya dari perubahan perilaku. Chaplin (1989) membedakan emosi dengan perasaan, parasaan (feelings) adalah pengalaman disadari yang diaktifkan baik oleh perangsang eksternal maupun oleh bermacammacam keadaan jasmaniah.

Crow \& Crow (1958), menjelaskan tentang emosi adalah "an emotion, is an affective experience that accompanies generalized inner adjustment and mental and physiological stirredup states in the individual, and that shows it self in his evert behaviour". Menurut Hurlock (1990), emosi adalah:

a. Dapat melakukan kontrol diri yang bisa diterima secara sosial Individu yang emosinya matang mampu mengontrol ekspresi emosi yang tidak dapat diterima secara sosial atau membebaskan diri dari energi fisik dan mental yang tertahan dengan cara yang dapat diterima secara sosial.

b. Pemahaman diri. Individu yang matang, belajar memahami seberapa banyak kontrol yang dibutuhkannya untuk memuaskan kebutuhannya dan sesuai dengan harapan masyarakat

c. Menggunakan kemampuan kritis mental. Individu yang matang berusaha menilai situasi secara kritis sebelum meresponnya, kemudian memutuskan bagaimana cara bereaksi terhadap situasi tersebut.

Emosional dapat dialami oleh siapapun, di manapun dan kapanpun, dan dalam kondisi apapun. Emosional dapat dimaknai adalah kondisi seseorang ketika menghadapi hal-hal yang menyebabkan pikiran, perasaan, sampai mentalnya mengalami perubahan sebagai responnya. Kesadaran tinggi yang dimiliki individu mampu mengontrol emosinya menjadi kecerdasan emosional. Ketika kecerdasan itu muncul, maka perilaku sikap pun akan terkontrol dengan baik.

Selain kecerdasan emosional yang menjadi faktor kesuksesan, Zohar dan Marshall (2000) menjelaskan bahwa kecerdasan spiritual juga memegang peranan yang besar terhadap kesuksesan seseorang dalam bekerja. Spiritual, menurut Oxford English Dictionary dapat diketahui dari arti kata-kata berikut: persembahan, dimensi supranatural, berbeda dengan dimensi fisik, perasaan atu pernyataan jiwa, kekudusan, sesuatu yang suci, pemikiran yang intelektual dan berkualitas, adanya perkem- 
bangan pemikiran dan perasaan, adanya perasaan humor, ada perubahan hidup, dan berhubungan dengan organisasi keagamaan. Burkhardt (1993) menjelaskan spiritualitas meliputi aspek-aspek berikut: 1) berhubungan dengan sesuatu yang tidak diketahui atau ketidakpastian dalam kehidupan, 2) menemukan arti dan tujuan hidup, 3) menyadari kemampuan untuk menggunakan sumber dan kekuatan dalam diri sendiri, dan 4) mempunyai perasaan keterikatan dengan diri sendiri dan dengan yang maha tinggi.

Secara etimologi, kata spiritual mengandung makna mengenai sesuatu yang mendasar, penting, dan mampu menggerakkan, serta memimpin cara berpikir dan bertingkah laku seseorang. Spiritualitas juga erat kaitannya dengan Yang Maha Kuasa sesuai dengan kepercayaan yang dianut oleh individu. Spiritual seseorang dipengaruhi oleh beberapa unsur, di antaranya adalah: unsur budaya, perkembangan, pengalaman hidup, kepercayaan dan ide-ide tentang kehidupan. Unsur-unsur spiritualitas meliputi kesehatan spiritual, kebutuhan spiritual, dan kesadaran spiritual. Sedangkan dimensi spiritual adalah suatu penggabungan yang menjadi satu kesatuan antara unsur psikologikal, fisiologikal, atau fisik, sosiologikal dan spiritual.

Spiritualitas dapat memberikan suatu perasaan yang berhubungan dengan: 1) intrapersonal (hubungan antara diri sendiri), 2) interpersonal (hubungan antara orang lain dengan lingkungan) dan 3) transpersonal (hubungan yang tidak dapat dilihat yaitu suatu hubungan dengan ketuhanan yang merupakan kekuatan tertinggi). Spiritual dikorelasikan juga dengan keyakinan yang dimiliki oleh seseorang. Keyakinan yang dimiliki tersebut bermakna bahwa individu harus berkomitmen terhadap sesuatu atau seseorang. Komitmen tersebut memberi konsekuensi tersendiri dalam tataran aplikasi, ketika komitmen diaplikasikan maka mucul sebuah kepercayaan. Konsep kepercayaan mempunyai dua pengertian. Pertama kepercayaan didefinisikan sebagai kultur atau budaya dan lembaga keagamaan seperti Islam, Kristen, Budha, dan lain-lain. Kedua, kepercayaan didefinisikan sebagai sesuatu yang berhubungan dengan Ketuhanan, Kekuatan tertinggi. Agama dimaknai sebagai sistem organisasi kepercayaan dan peribadatan dimana seseorang bisa mengungkapkan dengan jelas secara lahiriah mengenai spiritualitasnya. Agama adalah suatu sistem ibadah yang terorganisir dan teratur.

Kearifan Intelektual, Emosional, dan Spiritual merupakan suatu kondisi di mana kecerdasan intelektual, emosional, dan spiritual menjadi satu kesatuan yang mampu diaplikasikan dalam wujud nyata yakni berupa sikap/perbuatan/ perilaku dalam kehidupannya. Kearifan intelektual, emosional, dan spiritual sangat diperlukan individu dan kelompok dalam menghadapi berbagai tantangan zaman. Bagaimana peran intelektualitas sebagai komponen hardskill mampu memberi kontribusi dalam perkembangan ilmu pengetahuan dan teknologi yang semakin canggih, sedangkan emosional dan spiritual menjadi komponen softskill yang sangat penting untuk dimiliki juga. Ketika kearifan intelektual, emosional, dan spiritual dapat dimiliki individu maupun kelompok sebagai kesatuan keterampilan, maka mereka akan mampu menghadapi berbagai tantangan zaman dengan efektif, dan efisien

\section{Pemuda}

Manusia menjadi sumber daya paling potensial pada suatu negara, dan pemuda adalah salah satu sumber daya yang potensial tersebut. Seperti diungkap Fadjar (2001), "Terobosan yang paling menggairahkan dari abad 21 bukan karena teknologi, melainkan karena konsep yang luas tentang apa arti manusia". Sumber daya manusia-lah yang berperan dalam pembangunan suatu negara. Hal senada dijelaskan dalam konsep Naisbitt (1995), "Tepi Asia Pasifik telah memperlihatkan, negara miskinpun bangkit, tanpa sumber daya alam melimpah, asalkan negara melakukan investasinya yang cukup dalam hal sumber daya manusia".

Kelangsungan hidup suatu bangsa di masa depan menjadi tugas dan tanggung jawab para pemudanya. di pundak pemudalah beban berat dipikul. Untuk itu, pemuda harus mempersiapkan diri sebaik mungkin dengan berbagai potensi yang dimilikinya. Sejalan dengan ungkapan Salam (2000:65), bahwa: "Keberlangsungan perjalanan kehidupan berbangsa ada di tangan para generasi penerusnya", maka diharapkan generasi muda 
mampu memerankan tugasnya dengan baik serta menjaga keseimbangan agar identitas dan kebanggaan nasional tetap terjaga, bahkan jika mungkin diartikulasikan kembali.

Pemuda adalah individu yang bila dilihat secara fisik sedang mengalami perkembangan dan secara psikis sedang mengalami perkembangan emosional, sehingga pemuda merupakan sumber daya manusia pembangunan baik saat ini maupun masa datang. Definisi pemuda yang lainnya adalah individu dengan karakter yang dinamis, bahkan bergejolak dan optimis namun belum memiliki pengendalian emosi yang stabil. Pemuda menghadapi masa perubahan sosial maupun kultural.

Dalam kosa kata bahasa Indonesia, pemuda juga dikenal dengan sebutan generasi muda dan kaum muda. Seringkali terminologi pemuda, generasi muda, atau kaum muda memiliki definisi beragam. Definisi tentang pemuda di atas lebih pada definisi teknis berdasarkan kategori usia sedangkan definisi lainnya lebih fleksibel. Di mana pemuda/ generasi muda/kaum muda adalah mereka yang memiliki semangat pembaharu dan progresif. WHO (World Health Organization) menyebut pemuda dengan kata " young people". Batas usia mereka antara 10-24 tahun. Untuk usia 1019 tahun disebut "adolescenea" atau remaja. Sedangkan International Youth Year yang diselenggarakan tahun 1985, mendefinisikan penduduk berusia 15-24 tahun sebagai kelompok pemuda. Sedangkan menurut draf RUU Kepemudaan, Pemuda adalah mereka yang berusia antara 18 hingga 35 tahun. Menilik dari sisi usia maka pemuda merupakan masa perkembangan secara biologis dan psikologis. Berkenaan dengan kondisi pemuda yang penuh dinamika ini, maka pemuda selalu memiliki aspirasi yang berbeda dengan aspirasi masyarakat secara umum. Dalam makna yang positif aspirasi yang berbeda ini disebut semangat pembaharu.

\section{MEA (Masyarakat Ekonomi Asia)}

Terinspirasi oleh MEE (Masyarakat Ekonomi Eropa), MEA (Masyarakat Ekonomi ASEAN) akan hadir di kawasan Asia Tenggara, dan diberlakukan dipenghujung tahun 2015. Berbagai persiapan telah dilaksanakan untuk menghadapinya. Hal-hal yang harus dipersiapkan dalam pasar bebas ini adalah barang dan jasa, investasi, tenaga kerja profesional, dan juga aliran modal. Bukan sekedar perdagangan barang dan jasa, MEA juga menjadi pasar tenaga kerja profesional, seperti dokter, pengacara, akuntan, dan lainnya. Sejumlah pimpinan asosiasi profesi mengaku cukup optimistis bahwa tenaga kerja ahli di Indonesia cukup mampu bersaing di era pasar bebas.

Masyarakat Ekonomi ASEAN adalah bentuk integrasi ekonomi negara-negara yang tergabung di dalamnya adalah semua negaranegara yang berada dikawasan Asia Tenggara (ASEAN). Negara-negara ini akan menerapkan sistem perdagangan bebas. Kesepakatan untuk memberlakukan MEA atau ASEAN Economy Community (AEC) di kalangan negara-negara ASEAN sudah dibuat oleh Indonesia dan seluruh negara-negara ASEAN lainnya (9 negara lainnya) telah dibuat kurang lebih dua dekade yang lalu tepatnya Desember 1997 ketika KTT ASEAN yang diselenggarakan di Kota Kuala Lumpur, Malaysia disepakati adanya ASEAN Vision 2020 yang intinya menitikberatkan pada pembentukan kawasan ASEAN yang stabil, makmur, dan kompetitif dengan pertumbuhan ekomoni yang adil dan merata serta dapat mengurangi kemiskinan dan kesenjangan sosial.

Pembentukan pasar tunggal Masyarakat Ekonomi Asean (MEA) ini, memungkinkan satu negara menjual barang dan jasa dengan mudah ke negara-negara lain di seluruh Asia Tenggara sehingga kompetisi akan semakin ketat. MEA hadir untuk menyaingi negara Cina dan India, yang memang sangat mempengaruhi banyak orang, terutama pekerja yang berkecimpung pada sektor keahlian khusus. Staf Khusus Menteri Tenaga Kerja dan Transmigrasi, Dita Indah Sari, menjelaskan bahwa MEA mensyaratkan adanya penghapusan aturan-aturan yang sebelumnya menghalangi perekrutan tenaga kerja asing. "Pembatasan, terutama dalam sektor tenaga kerja profesional, didorong untuk dihapuskan," katanya. "Sehingga pada intinya, MEA akan lebih membuka peluang tenaga kerja asing untuk mengisi berbagai jabatan serta profesi di Indonesia yang tertutup atau minim tenaga asingnya."

Diharapkan MEA yang sudah diambang pintu, dapat menginspirasi dan memotivasi anak bangsa untuk lebih meningkatkan 
kompetensinya agar mampu bersaing di pasar bebas MEA. Berbagai hambatan tantangan yang dihadapi perlu disikapi positif untuk menjadikan negara Indonesia Berjaya dengan karakter dan kelebihan yang dimilikinya.

\section{PENUTUP}

Pemuda diharapkan mampu bersaing dengan bangsa-bangsa lain untuk dapat mengambil kesempatan yang ada. Maka sudah selayaknya potensi yang dimiliki harus dieksplorasi dengan baik. Pemuda memiliki karakter yang unik dengan segala potensi yang dimilikinya. Kelebihan yang dimiliki pemuda hendaknya dieksplorasi secara maksimal. Terlebih di era global yang begitu kompetitif. Untuk mengantisipasi hal-hal yang tidak diinginkan, pemuda Indonesia harus sedini mungkin mempersiapkan diri untuk menghadapi globalisasi, salah satunya menggeluti Masyarakat Ekonomi ASEAN (MEA). Berbagai persiapan untuk menyambut pasar bebas ASEAN ini sudah dilaksanakan. Bukan hanya intelektual saja yang harus dipersiapkan, masalah emosional, dan spiritual.

Dalam tataran aplikasi, intelektualitas yang terus menerus dididik melalui pendidikan baik formal, informal, maupun non formal, belum cukup untuk bekal hidup, maka pemuda harus dibekali dengan nilai-nilai spiritual sebagai benteng dalam menghadapi berbagai tantangan zaman, diharapkan emosi pemuda yang cenderung labol dapat dilatih untuk lebih stabil. juga mampu dilatih belum tidak mampu di yang apabila tidak diasah akan menjadi sesuatu yang merugikan, namun ketika kearifan Intelektual, emosional, dan spiritual para pemuda sangat diperlukan dalam menghadapi pasar bebas ASEAN. Berbagai tantangan akan dihadapi oleh para pemuda lebih berat dari sebelumnya. Hal ini disebabkan kompetisi semakin tinggi. Mereka harus bersaing dengan berbagai bangsa di Asia Tenggara. Tak hanya perdagangan dan jasa, MEA juga menyangkut pasar tenaga profesional. Sumber daya manusia Indonesia yang unggul secara kuantitas, diharapkan unggul juga secara kualitas.

Kearifan intelektual, emosional, spiritual menjadi sangat penting ketika sesuatu yang baru hadir di dalam kehidupan. Namun, menyangkut kompetensi arif adalah suatu sikap yang ditampilkan oleh manusia sebagai respon dari permasalahan yang dihadapi. Kearifan yang dimunculkan dalam kehidupan sehari-hari akan menjadi karakter dari orang tersebut.

Berbagai kesempatan dan peluang baik dapat diraih oleh para pemuda harapan bangsa demi meningkatkan harkat dan martabat bangsa. Kondisi ini tentu bukan sesuatu yang mudah, karena mereka harus berkompetisi dengan berbagai bangsa di wilayah Asia Tenggara, namun juga tidak sulit, ketika kesiapan fisik dan psikis dilaksanakan dengan sebaik-baiknya guna dapat meraih kesempatan dan peluang emas yang sudah di depan mata. Diharapkan negara Indonesia dengan masyarakat yang besar baik secara kualitas maupun kuantitas, mampu bersaing di pasar bebas dengan kearifan intelektual, emosional dan spiritual yang dimilikinya.

\section{DAFTAR PUSTAKA}

Fajar, A. (2003) Pengembangan Sikap Nasionalisme dalam Pembelajaran PPKn Melalui Pendekatan SainsTeknologi-Masyarakat (S-T-M) Pada Pokok Bahasan "Kesetiaan" (Studi Eksperimental di SMU Negeri 8 Bandung). Tesis Magister PPS UPI: Bandung

Naisbitt, J. (1995). Mega Trend AsiaDelapan Mega Trend Asia yang Mengubah Dunia, Jakarta: Gramedia Pustaka Utama

http://artikata.com/arti-358240-kearifan.html http://kbbi.web.id/arif http://kamus.cektkp.com/kearifan/ https://www.facebook.com/KomunitasIlmiahM ahasiswa/posts/358636784231276

http://kbbi.web.id/intelektual https://id.wikipedia.org/wiki/Emosi https://lp2mkita.wordpress.com/2010/05/04/pen gertian-emosi-dan-emosional/

https://nezfine.wordpress.com/2010/05/05/peng ertian-spiritual/

http://www.scribd.com/doc/58789726/Pengerti an-Spiritual\#scribd

http://www.bbc.com/indonesia/berita_indonesia /2014/08/140826_pasar_tenaga_kerja_aec http://file.upi.edu/Direktori/FIP/JUR._ADMINI STRASI_PENDIDIKAN/1979071220050 11-NURDIN/KARYA_ILMIAH_8.pdf http://repository.usu.ac.id/bitstream/123456789 /17541/1/log-apr2009-5\%20(4).pdf 